\title{
Localized Pleural Malignant Mesothelioma
}

National Cancer Institute

\section{Source}

National Cancer Institute. Localized Pleural Malignant Mesothelioma. NCI Thesaurus. Code C45666.

A malignant mesothelioma that arises from the pleura with the gross appearance of a localized nodular lesion without gross or microscopic evidence of diffuse pleural involvement. 